\title{
Geochemical fractionation of Heavy metals in the sediment at the point of discharge of Iyalaro stream into Lagos Lagoon
}

\author{
I.A. Ladigbolu ${ }^{1 *}$, J. Appia ${ }^{1}$, K.J. Balogun ${ }^{1}$, and A.K. Adedeji ${ }^{1}$ \\ "Nigerian Institute for Oceanography \& Marine Research, Victoria Island, Lagos
}

\begin{abstract}
Sequential extraction by Tessier et al; 1979 was used to study the geochemical fractionation of the following heavy metals; cadmium, chromium, Nickel, lead and zinc in the sediments collected at the point of discharge of Iyalaro stream into Lagos Lagoon to understand their mobility and bioavailability. The highest percentage (\%) of all heavy metals studied were observed in the oxidisible fraction; $\mathrm{Cd}(40.3) \%, \mathrm{Cr}(35.9) \%$, $\mathrm{Pb}(42.6) \%, \mathrm{Zn}(41.8) \%$ except $\mathrm{Ni}$ (42.6) \% which was observed at residual / lithogenous (crystal lattice or silicates bound) fraction of the sediment. High $\mathrm{Cr}$ (31.2) \% contribution was also observed in the residual fraction, this is an indication that rock / soil weathering / formation is also playing meaningful contribution to the presence of $\mathrm{Ni}$ and $\mathrm{Cr}$ in the studied area. Sequential extraction for the speciation of elements among the geochemical phases in this study indicated that most of the metals studied were in exchangeable, carbonate bound, reducible (Fe-Mn oxides) and oxidisable (organic matter/sulphide bound) fractions which are potentially available fractions, and contributed by anthropogenic activities. The order of reducing availability of the studied heavy metals were as follow; $\mathrm{Zn} \mathrm{(93.2)} \mathrm{\%} \mathrm{>} \mathrm{Pb} \mathrm{(81.6)} \mathrm{\%} \mathrm{>} \mathrm{Cd} \mathrm{(73.1)} \mathrm{\%} \mathrm{>} \mathrm{Cr} \mathrm{(68.8)} \mathrm{\%} \mathrm{>} \mathrm{Ni} \mathrm{(57)}$ $\%$. Therefore, under favourable biogeochemical processes for remobilization of the studied metals from the sediment, the studied metals can get the water body heavily polluted, impact food chain and become an environmental risk.
\end{abstract}

Keywords: Sequential extraction, geochemical fractionation, sediments, food chain.

\section{Introduction}

Sediment receives toxic elements from both natural and a wide range of anthropogenic sources and several authors have identified that in order to understand forms in which these elements exist in the aquatic biota; speciation study in the sediment is crucial. Chemical speciation of sediment is defined as the identification and quantification of the forms in which metals or elements occurs in the sediment.

Metals in the sediments through speciation study can be classified into two major geochemical phases namely lithogenous (immobile) and non - lithogenous (mobile). Lithogenous or residual fraction metals are not available in long term for bio - uptake, due to strong bond which exists between these metals and crystal lattice of silicate of the sediments and soils. Therefore, they are from natural source that is rock or soils weathering while non- lithognous fractions metals are readily available in short term (Badri and Anston, 1983). Nonlithogenous (mobile) fraction can be further subdivided into exchangeable fraction, carbonate bound fraction, reducible (Fe-Mn oxides / hydroxides) fraction and oxidisable (organic matter / sulphide) fraction (Bancroft et al; 1981).

Metals associated with these four mobile fractions, most of time originate from anthropogenic sources and readily available for uptakes and bioaccumulation in aquatic biota, although their availability depend on $\mathrm{pH}$, redox- potential and temperature (Gambrell, 1994, Schlinder, 1991).

A comprehensive knowledge of chemical speciation and total metal concentration give proper understanding of the interaction between the trace elements and sediments. It explains the environmental impact of these metals and reliably predicted their sources (i.e. anthropogenic and natural (rock or soil weathering), mobility, bioavailability, distribution and toxicity in the environment.

Therefore, the orientation of this study is to study the geochemical fractionation and bioavailability of the following heavy metals $\mathrm{Cd}, \mathrm{Cr}, \mathrm{Ni}, \mathrm{Pb}$ and $\mathrm{Zn}$ in the sediments of the outfalls of Iyalaro stream into Lagos Lagoon and their tendency of causing health hazard.

\subsection{Description of the Study Area}

\section{Materials and Methods}

\subsubsection{Study Area}

The study area is the outfall of Iyalaro stream into Lagos Lagoon with Latitude N6 ${ }^{0} 33^{\prime} 53.91^{\prime \prime}$ and Longitude E $3^{0} 24^{\prime} 04.21$ ". Iyalaro stream is an important stream due to the fact that it receives industrial effluents from the array of industries located along its course. It is a potential source of pollution to Lagos Lagoon. The stream flows into Ogudu canal, where it eventually emptied into Lagos Lagoon (Figure 1). The 
choice of the study point is to have a clear understanding of how the reported contaminated stream would affect Lagos Lagoon at the point at which its discharge.

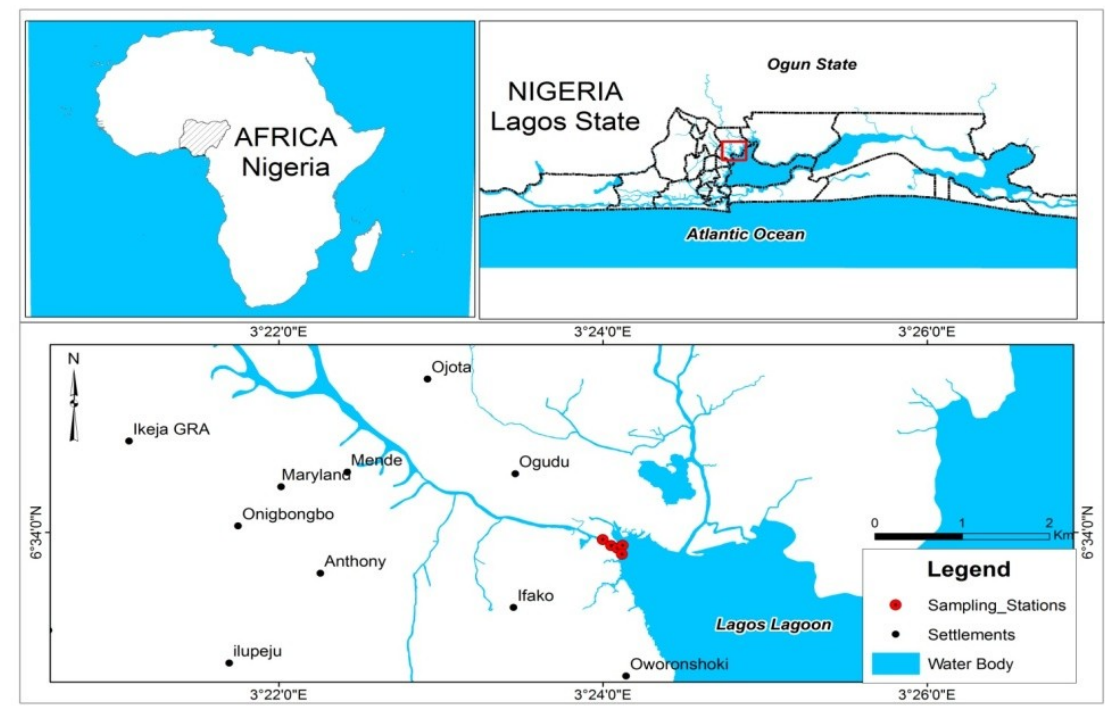

Figure 1.Map depicting the sampling area in Lagos Lagoon

\subsubsection{Sampling Techniques}

Five Sediment samples were collected from where Iyalaro stream emptied into Lagos Lagoon to represent the entire study area with aid of van - veen grab. The five samples were thoroughly mixed together to make a composite sample and transferred into a pre- treated black polythene bags, kept in the ice cooler and transported to laboratory, air - dried, homogenized and sieve with $2 \mathrm{~mm}$ sieve. The representative samples for the experiments were obtained from the composite samples through both coning and quartering processes.

In this study Tessier et al; 1979, sequential extraction procedures were used to determine the operational speciation / geochemical fractionation of heavy metals in the sediment at the outfall of Iyalaro stream into Lagos Lagoon to understand both the actual and potential mobility of these metals. The method was chosen because it is very simple, accurate and cost effective.

\subsubsection{Analysis of sediment}

$1 \mathrm{~g}$ of the sediment representative sample was digested with $25 \mathrm{ml}$ of ratio $3: 1$ Hydrochloric and Nitric acid (aqua regia) until the volume reduced to about $5 \mathrm{ml}$, filter and make up with distil water to $50 \mathrm{ml}$ for total metal concentration.

$1 \mathrm{~g}$ representative sample was used for sequential extraction of heavy metals in accordance with Tessier et al., 1979.

Sequential extraction procedure: $1 \mathrm{~g}$ sediment was extracted in the following order:

Fraction 1: Dissolved or Exchangeable fraction: 1M magnesium chloride $(25 \mathrm{ml}), \mathrm{pH} 7.01$ shaking for $1 \mathrm{hr}$ at $25^{0} \mathrm{C}$.

Fraction 2: Carbonate bound fraction (acid soluble): $1 \mathrm{M}$ sodium acetate $(25 \mathrm{ml}), \mathrm{pH} 5.04$ with acetic acid, $6 \mathrm{hr}$ shaking at $25^{\circ} \mathrm{C}$.

Fraction 3: Fe-Mn oxide bound fraction (reducible): $0.04 \mathrm{M}$ hydroxylamine hydrochloride in acetic acid (25\% $\mathrm{v} / \mathrm{v}), 25 \mathrm{ml}$, shaking $6 \mathrm{hr}$ at $96^{\circ} \mathrm{C}$.

Fraction 4: Organic bound fraction (oxidizable): $0.02 \mathrm{M}$ nitric acid $(6 \mathrm{ml})+30 \%$ hydrogen peroxide $(9 \mathrm{ml}), 2$ hrs occasional shaking at $850 \mathrm{C}$, additional $9 \mathrm{ml}$ of $30 \%$ hydrogen peroxide with continuation of shaking at $85^{\circ} \mathrm{C}$ for 3 hrs.

Fraction 5: Residual fraction (bound to silicates and detritus materials): Total digestion with concentrated mixture of nitric acid and perchloric acid $(3: 1 \mathrm{v} / \mathrm{v})$

Triplicate analyses of heavy metals in the sediment were carried out on both the total metal concentration and sequential extraction samples using Atomic Absorption Spectrophotometer, Bulk scientific 200 A model. 
III. Results and Discussions

Table 1: Concentration of heavy metals in sediments of outfall of Iyalaro stream into Lagos Lagoon (mg/kg)

\begin{tabular}{|l|l|l|l|l|l|l|l|l|}
\hline Metals & F1 & F2 & F3 & F4 & F5 & Total(mg/kg) & $\begin{array}{l}\text { Pseduototal } \\
(\mathrm{mg} / \mathrm{kg})\end{array}$ \\
\hline $\mathrm{Cd}$ & 0.73 & 2.18 & 5.40 & 10.20 & 6.80 & $25.30 \pm 2.50$ & $26.60 \pm 3.43$ \\
\hline $\mathrm{Cr}$ & 1.71 & 6.04 & 8.30 & 17.50 & 15.20 & $48.75 \pm 4.32$ & $49.40 \pm 4.52$ \\
\hline $\mathrm{Ni}$ & 0.94 & 3.76 & 2.55 & 7.05 & 10.65 & $25.00 \pm 6.45$ & $28.50 \pm 5.63$ & 105.1 \\
\hline $\mathrm{Pb}$ & 0.18 & 0.52 & 20.45 & 23.15 & 10.00 & $54.03 \pm 5.10$ & $52.30 \pm 6.71$ & 96.3 \\
\hline $\mathrm{Zn}$ & 16.20 & 30.10 & 29.75 & 61.80 & 10.10 & $148.00 \pm 9.05$ & $152.90 \pm 10.32$ & 103.3 \\
\hline
\end{tabular}

Figure 2: Metals in the sediment at each extraction stage of sequential extraction procedure and residual fraction

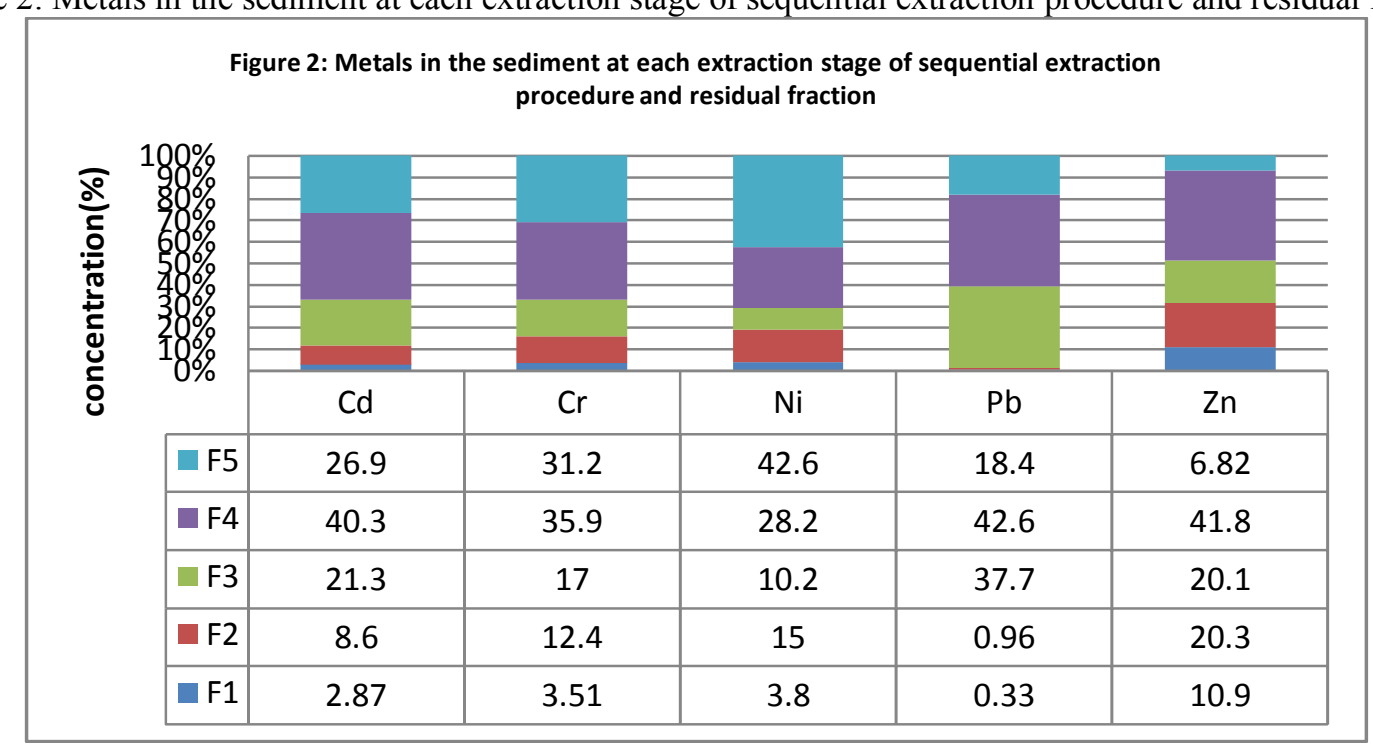

\subsection{Discussions}

In this study the sequential extraction procedure provides information on mobility and bioavailability of metals in the sediment through metals partitioning pattern in the sediment.

Heavy metals in both exchangeable (F1) and carbonate (F2) fractions of sediment are relatively mobile and are readily available for biological uptake, a process facilitated by the low $\mathrm{pH}$. In this study, exchangeable and carbonate fraction accounts for $\mathrm{Pb}$ of about $1.3 \%$ of the total metal concentration while $\mathrm{Ni}, \mathrm{Cr} \& \mathrm{Cd}$ contribution ranges from $11.47-18.8 \%$. Zn has the highest value of $31.2 \%$ of the total metal concentration in the fraction. This high concentration of carbonate - exchangeable $\mathrm{Zn}$ in this study was in agreement with the result of Nussmann, 1965 for Lake Superior and suggested that this $\mathrm{Zn}$ is probably due to anthropogenic sources, entered the sediment as absorbed ions or carbonate species (Lorraine and Robert, 1979).

Reducible fraction (F3) metals associated with hydrous iron oxides and $\mathrm{Mn}$ - oxides, co precipitate or sorption onto pre - existing oxides coating. This fraction is a sink for heavy metals under oxidizing condition. Mobility of metals in this fraction are redox potential dependent; that is relatively small changes in redox potential toward reducing conditions would cause reduction of Fe and Mn oxides species. This would cause dissolution of $\mathrm{Fe}$ and $\mathrm{Mn}$ oxide mineral, thereby release associated metals. $\mathrm{Pb}$ has the highest percentage in this fraction $37.7 \%$ while $\mathrm{Cd} \& \mathrm{Zn}$ shown moderate affinity of $21.3 \%$ and $20.1 \%$ respectively for the oxides, $\mathrm{Cr}$ and Ni exhibited low to average affinity of $10.2 \%$ and $17 \%$ respectively for the same fraction (fig.2). The highest percentage of $\mathrm{Pb}$ in the reducible fraction is due to the fact that $\mathrm{Pb}$ can form stable complexes with $\mathrm{Fe}$ and $\mathrm{Mn}$ dioxide. The predominant of $\mathrm{Pb}$ in the reducible fraction is in agreement with the reports of Fernandes, 1997, $\mathrm{Li}$ et al., $2001 \mathrm{Ip}$ et al., 2007.

Oxidisable (organic matter / sulphide) fraction (F4) is the fourth fraction of the non - lithogenous phase and metals in this fraction in the sediment are potentially available. Metals in organic bound fraction are not considered very mobile due to their association with higher molecular weight stable humic substances. Mobility of metals in this fraction can be achieved by decomposition processes and degradation of organic matter under oxidizing condition. In this study $\mathrm{Pb}, \mathrm{Zn} \& \mathrm{Cd}$ have higher percentage of their total metal concentration ranges from $40.3 \%-42.6 \%$ in the fraction while high to moderate percentage total metal concentration of $\mathrm{Cr}(35.9 \%)$ and $\mathrm{Ni}(28.2 \%)$ were observed in the fraction.

Lithogenous / residual (crystal lattice of silicate bound) fraction (F5) is the most stable metal fraction in the soil and sediment due to the fact that the metals in these fractions are occluded in the crystal lattice of silicate and well crystallized oxide minerals. Metals in this fraction could be taken as a non - available metals 
and source of these metals in the fraction is natural source that has to do with soil or rock weathering. In this study less than $50 \%$ contribution of studied metals in the residual fraction has shown that natural source is not a major source of these metals in the sediment of the studied area.

\subsubsection{Availability of heavy metals}

According to Tessier et al., 1979 Metals associated with the first four fractions of sequential extraction were considered as readily available metals to the water column and biota while metals in the lithogenous or residual phase are considered as non - available metals.

Therefore, summation of the percentage total metal concentration $(F 1+F 2+F 3+F 4)$ of each of the studied metals in the first four fractions of the studied sediment is equivalent to the total percentage of available metal. The total percentage of availability of all the studied metals were as follow $\mathrm{Zn}(93 \%), \mathrm{Pb}(82 \%), \mathrm{Cd}$ (73\%), $\mathrm{Cr}(69 \%)$ and $\mathrm{Ni}(57 \%)$ and their decreasing order of availability in the studied sediment are $\mathrm{Zn}>\mathrm{Pb}>$ $\mathrm{Cd}>\mathrm{Cr}>\mathrm{Ni}$.

The high percentage of more than $50 \%$ of the studied metals associated with the non - lithogenous (non - residual) phase confirmed that they are from anthropogenic activities and they can be easily transferred into the food chain through water reservoirs, uptakes by plant and aquatic organism. Consequently, there is need for concern about the levels of the studied metals that are potential available in the sediment of the studied environment, since it is a cumulative poison for mammals.

\subsection{Conclusion}

The distribution of heavy metals among the various geochemical fractions in the studied sediments have shown that more than $50 \%$ of the studied metals were in the non - lithogenous fraction, therefore, they can be available for uptakes by plant, transferred into the food chain and become an environmental risk. It has also shown that anthropogenic activities are major sources of the metals in the sediment. Therefore, it is necessary for Lagos state Environmental protection Agency (LASEPA) and NESTRA to put a measure in place that would ensure contamination free aquatic environment.

\section{References}

[1]. A.V. Filgueiras, I. Lavilla and C. Bendicho, Chemical Sequential Extraction for metal Partitioning in environmental solid samples. J. Environ. Monit. 4, 2002, 823-857.

[2]. M.A. Badri and S.R. Aston, Observation of heavy metal geochemical associations in polluted and non - polluted estuarine sediments. Environ. Pollution; 6 (series B),1983, 181 - 193.

[3]. B. Kumar, S. Kumar, M. Mishra, S.K. Singh, D. Prakash, C.S. Sharma and D.P. Mukherjee, Geochemical fractionation of some heavy metals in the soil in the vicinity Sukinda mining Area, Orissa. Advances Applied Science Research, Pelagia Research Library. 2 (5), 2011, 263- 272.

[4]. H.M. Fernandes, Heavy metal distribution in sediments and ecological risk assessment: the role of diagenetic processes in reducing metal toxicity in bottom sediment. Environmental pollution 97, 1997, 317- 325.

[5]. R.P. Gambrell, Trace and Toxic metals in Wetland - A review. J. Environ. Qual. Vol. 23,1994, 883- 891.

[6]. C.C.M. Ip, X .D. Li, G. Zhang, O.W.H. Wai, Y. S. Li, Trace metal distribution in sediments of the Pearl River Estuary and the surrounding coastal area, south China. Environmental pollution 147, 2007, 311- 323.

[7]. X. Li, Z. Shen, O.W.H. Wai, Y.S. Li, Chemical forms of Pb, Zn and Cu in the sediment profiles of the Pearl River Estuary. Marine Pollution Bulletin 42, 2001, 215 - 223.

[8]. L. H. Filipek and R. M. Owen, Geochemical Associations and Grain- size Partitioning of Heavy Metals in Lacustrine Sediments. Chemical Geology, 26, 1979, $105-117$.

[9]. P. O’Neill, J. Williams, K. C. C. Bancroft, R. D. Davies and J. A. Campbell, Int. Conference on Heavy Metals in the Environment, Athens, Greece, vol. 1, 1985, 582

[10]. P.W. Schlinder, The regulation of heavy metal concentrations in the natural aquatic systems. In Heavy Metals in the Environment 1. (Ed) Vernet J - P. Elsevier Amsterdam, London. New York and Toyko, 1991, 95- 124.

[11]. S. Tokaliogu, S. Kartal and G. Birol, Application of a Three- stage Sequential Extraction procedure for the Determination of Extractable Metal Contents in Highway Soils. Turk. J. Chem. 27, 2003, 333- 346

[12]. A.Tessier, P.G.C Campbell, M. Bisson, Sequential Extraction procedure for the Speciation of Particulate Trace metals. Anal. Chem. $51,1979,844-851$

[13]. X. Xian, Chemical partitioning of Cadmium, Zinc, lead and copper in soils near samelters. J. Environ. Sc Health A 6, 1989, 527541

About the Corresponding Author, his name is Ladigbolu, I.A., a senior research officer in the department of Physical and Chemical Oceanography of the Nigeria Institute for Oceanography and Marine Research. He is a graduate of University of Ibadan, Oyo state, Nigeria. He holds B.sc in Chemistry and M.sc in Analytical Chemistry in 1995 and 1998 respectively. 